\title{
SLOPE STABILITY ANALYSIS USING GIS
}

\author{
Ahmed Bouajaj ${ }^{\mathrm{a}, *}$, Lahcen Bahi ${ }^{\mathrm{a}}$, Latifa Ouadif ${ }^{\mathrm{a}}$ and Mohamed Awa ${ }^{\mathrm{a}}$ \\ a3GIE Laboratory, Mohammadia Engineering School, Mohammed V University in Rabat, Morocco \\ E-Mail: ahmed.bouajaj@gmail.com
}

KEY WORDS: Slope Stability, GIS, Hovland Method, Safety factor.

\begin{abstract}
An analysis of slope stability using Geographic Information System (GIS) is presented in this paper. The methodology is based on the calculation of the safety factor in 2D and 3D using ArcGis. Hovland's Method in 3D and 2D were used in the stability analysis of the slope located at the 34 kilometer point (K.P.34) on the highway in the North of Morocco connecting Tangier to Ksar Sghir. Results shows that the safety factors obtained in 3D are always higher than those obtained in 2D and the slope becomes unstable when the water table level is less than $1 \mathrm{~m}$.
\end{abstract}

\section{INTRODUCTION}

Slope stability problems are frequently encountered in the construction of roads, canals, dikes and dams. Moreover, some natural slopes are or may become unstable. Slope failure can be catastrophic and cause loss of life and considerable damage.

The study of a slope includes, besides the recognition of the site and the choice of the mechanical characteristics of the soil, a stability calculation to determine firstly failure curve along which the slip risk is highest, secondly the corresponding value of the safety factor.

Slope stability analysis is applied by two-dimensional 2D and three-dimensional 3D analyses. In slope stability analysis, it is clear that a three-dimensional 3D situation may become important in cases where the geometry of the slope and slip surface varies significantly in the lateral direction, the material properties are highly anisotropic, or the slope is locally loaded (Chang, 2002)

There are several methods of slope stability analysis in 2D and 3D: Limit equilibrium methods (LEM) and Finite Element Methods (FEM)

Limit equilibrium methods have been the primary method used in estimating the stability of slope for decades. The procedures are based on finding a safety factor (SF) for the slope. It is useful for example to know exactly what percentage the $3 \mathrm{D}$ safety factor is higher than the $2 \mathrm{D}$ analysis.

3D Limit equilibrium methods for slope stability analysis are traditionally based on an extension of 2D Limit equilibrium methods analysis. The slicing method in 2D analyses has been extended into 3D analysis with columns by various authors due to the popularity of $2 \mathrm{D}$ LEM slicing methods.

Many 3D analysis methods of slope stability problems have been proposed.(Hovland, 1977; Chen and Chameau, 1982; Gens et al.1988; Lam and Fredlund, 1993; Huang et al. 2002 and zheng 2012.)

\footnotetext{
* Corresponding author
}

A geographical information system (GIS) is a relatively new software tool for geotechnical engineers (Carraea et al.1995), it become an important tool for landslide susceptibility mapping because it provides various functions of capturing, inputting, manipulating, visualizing, combining, querying, analyzing, modeling, and outputting of the geospatial data.

At the same time, using GIS can easily and effectively analyze the problem of 3D slope stability if a GIS based geotechnical analysis model can be used. Some researchers have integrated GIS in the analysis of slope stability (Van Westen, 1995 and Dai et al. 2001).

This paper presents a methodology based on the calculation of the safety factor in $2 \mathrm{D}$ and $3 \mathrm{D}$ using the Arcgis 9.3.

\section{DATA AND METHODOLOGY}

\subsection{Data}

The studied slope is located at the 34 kilometer point (K.P.34) on the highway in the North of Morocco connecting Tangier to Ksar Sghir (figure 1).

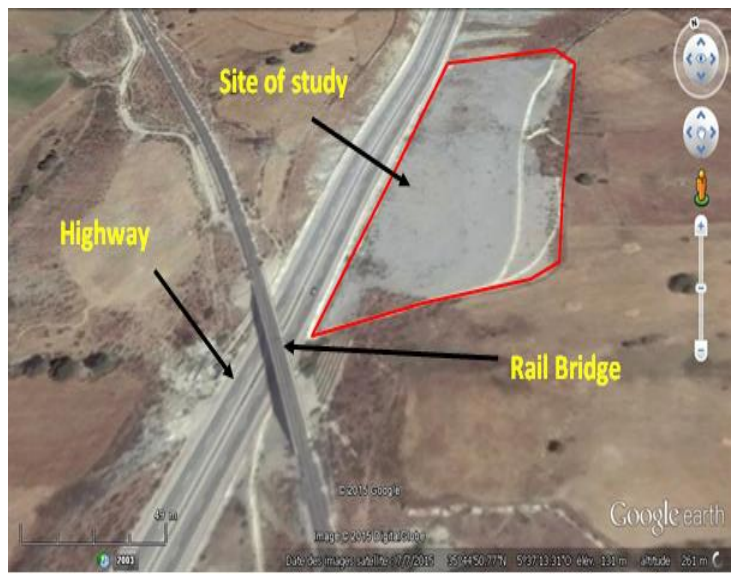

Figure 1. Location of the study area

Digital terrain models (DTM) of the studied site was built from topographical surveys, and then the slope and aspect 
have been determined for each pixel of the studied slope (figure 2).

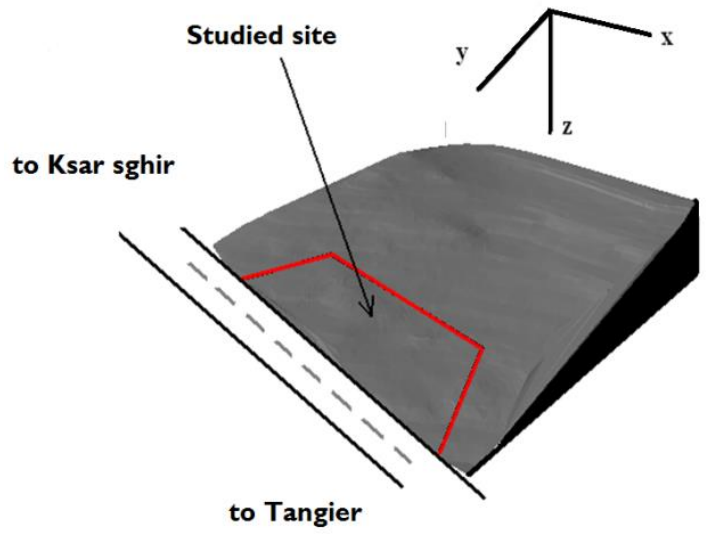

Figure 2. Studied Slope

\subsection{Methodology}

There are various methods of 2D stability analysis available in practice .Hovland (1977) proposed a new approach for the 3D slope stability analysis.

Hovland's method is an extension of the assumptions used in the two-dimensional ordinary method of slice, but columns were used instead of slices. Hovland's method neglects all the inter-column forces acting on the sides of the columns. The shear and normal forces acting on the base of each column are derived as components of the weight of the column.

For Hovland's three-dimensional method, the safety factor is acquired by dividing the soil mass above the failure surface into a number of equal sized vertical soil columns assuming the $\mathrm{x}$ and $\mathrm{y}$-coordinates are perpendicular and in the horizontal plane. The $\mathrm{z}$ coordinate is vertical (elevation) and the y-coordinate is to be set to the direction of the down slope movement of the failure block. The area of the soil column within the xy plan is defined by $\Delta \mathrm{X}$ and $\Delta \mathrm{Y}$. By assuming both the $\Delta \mathrm{X}$ and $\Delta \mathrm{Y}$ values are constant for all columns. Hovland defines the three-dimensional safety factor as the ratio of total available resistance along the failure surface over the total mobilized stress along it the three dimensional safety factor for Hovland's method is as follows:

$$
F S_{3 D}=\frac{\sum_{x} \sum_{y}\left[\operatorname{co} A+(W \operatorname{Cos}(\operatorname{Dip})-U) \operatorname{Tan} \phi^{\prime}\right]}{\sum_{x} \sum_{y} W \operatorname{Sin} \alpha_{y z}}
$$

In which $\alpha_{\mathrm{xz}}$ and $\alpha_{\mathrm{yz}}$ are Dip angles in their respective planes(figure 3 ), where:

$$
\begin{aligned}
& W=\gamma z \Delta x \Delta y \\
& \theta=\operatorname{ArcCos}\left(\operatorname{Sin} \alpha_{x z} \operatorname{Sin} \alpha_{y z}\right) \\
& A=\Delta x \Delta y\left(\frac{\sqrt{1-\operatorname{Sin}^{2} \alpha_{x z} \operatorname{Sin}^{2} \alpha_{y z}}}{\cos \alpha_{x z} \cos \alpha_{y z}}\right) \\
& U=\gamma_{w} h_{w} \frac{\sin \theta}{\cos \alpha_{x z} \cos \alpha_{y z}}
\end{aligned}
$$

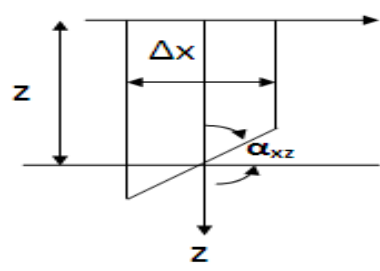

(a)

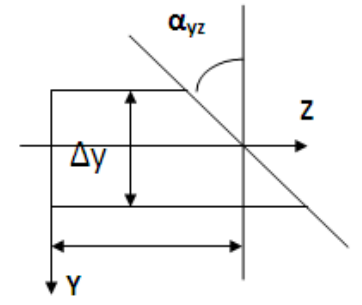

(b)

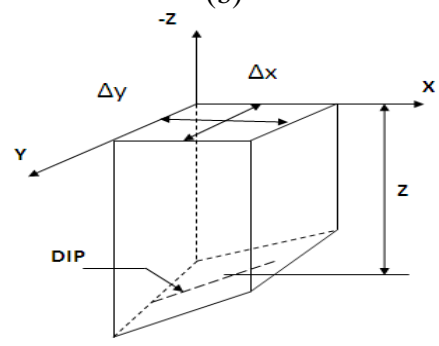

(c)

Figure.3: Section(a,b), and Three-Dimensional Views of one Soil Column Hovalnd (1977)(c)

Hovland's formula (1) can explained below by:

$$
F S_{3 D}=\frac{\begin{array}{c}
\sum_{x} \sum_{y}\left[\frac{c^{\prime} \Delta x \Delta y \operatorname{Sin} \theta}{\operatorname{Cos} \alpha_{x z} \operatorname{Cos} \alpha_{y z}}+(\gamma z \Delta x \Delta y \operatorname{Cos}(\text { dip })\right. \\
\left.\left.-\gamma_{w} h_{w} \frac{\Delta x \Delta y \operatorname{Sin} \theta}{\operatorname{Cos} \alpha_{x z} \operatorname{Cos} \alpha_{y z}}\right) \operatorname{Tan} \phi^{\prime}\right]
\end{array}}{\sum_{x} \sum_{y} \gamma z \Delta x \Delta y \operatorname{Sin} \alpha_{y z}}
$$

For $\alpha_{\mathrm{xz}}=0$, the safety factor in $2 \mathrm{D}$ can be expressed by

$$
\begin{array}{r}
\sum_{y}\left[\frac{c^{\prime} \Delta y \operatorname{Sin} \theta}{\operatorname{Cos} \alpha_{y z}}+(\gamma z \Delta y \operatorname{Cos}(\text { dip })\right. \\
F S_{2 D}=\frac{\left.\left.-\gamma_{w} h_{w} \frac{\Delta y \operatorname{Sin} \theta}{\operatorname{Cos} \alpha_{y z}}\right) \operatorname{Tan} \phi^{\prime}\right]}{\sum_{y} \gamma z \Delta y \operatorname{Sin} \alpha_{y z}}
\end{array}
$$

Where $\theta=\frac{\pi}{2}$

Raster Calculator tool of ArcGIS 9.3 that is a part of the Spatial Analyst function was used to calculate the 3D and 2D safety factors for each pixel using Hovland method.

\section{RESULTS AND DISCUSSION}

The piezometric measurements revealed that the water table level varies from $0.5 \mathrm{~m}$ to $4 \mathrm{~m}$.

In the case of high water tables, $(\mathrm{Hw}=0,5 \mathrm{~m}$ and $\mathrm{Hw}=1 \mathrm{~m})$, the safety factors in 2D and $3 \mathrm{D}$ are less than 1 , which 
indicates that the studied slope is unstable in the case of a rise of the water table at these depths.

For the water table depths $(\mathrm{Hw}=2 \mathrm{~m}, \mathrm{Hw}=3 \mathrm{~m}, \mathrm{Hw}=4 \mathrm{~m})$ we note that the safety factors (In 2D and 3D) are greater than 1 ,so the slope is in theory stable in the case of a considerable lowering of the water table at these depths. These results, thus, show that the height of the water table and the water pressure distribution play an important role on the shear strength and on the safety factor in $2 \mathrm{D}$ and 3D(figure 4).

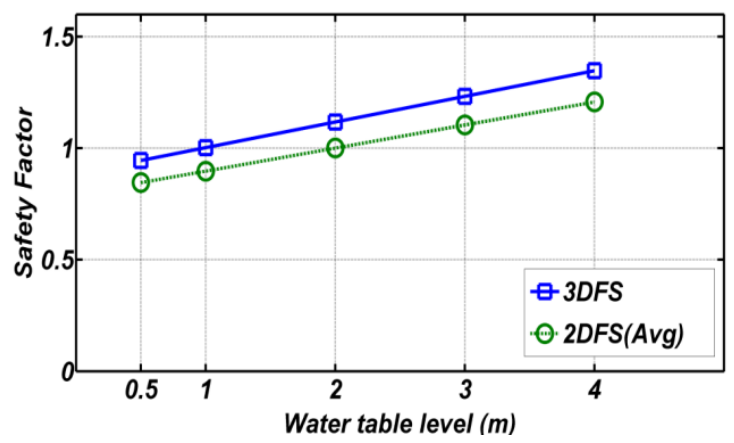

Figure 4. Influence of the water table level on the safety factor.

The 2D safety factor was calculated on three sections of the study area. The results of 2D stability analysis show that the safety factors differ in the three sections (table.1).

\begin{tabular}{|c|c|c|c|c|c|}
\hline $\begin{array}{c}\text { Water } \\
\text { table } \\
\text { Hw } \\
(\mathbf{m}) \\
\end{array}$ & 3D FS & $\begin{array}{c}\text { 2D FS } \\
\text { (avg) }\end{array}$ & $\begin{array}{l}\text { 2D FS } \\
\text { (Left) }\end{array}$ & $\begin{array}{c}\text { 2D } \\
\text { FS } \\
\text { (mid) }\end{array}$ & $\begin{array}{c}\text { 2D FS } \\
\text { (Right) }\end{array}$ \\
\hline 0.5 & 0.944 & 0.845 & 0.868 & 0.798 & 0.874 \\
\hline 1 & 1.002 & 0.897 & 0.920 & 0.847 & 0.928 \\
\hline 2 & 1.117 & 1 & 1.026 & 0.946 & 1.034 \\
\hline 3 & 1.232 & 1.104 & 1.132 & 1.043 & 1.141 \\
\hline 4 & 1.347 & 1.207 & 1.238 & 1.141 & 1.247 \\
\hline
\end{tabular}

Table1. Calculated safety factor results.

Also the lower values of the Safety factors are those obtained from the middle section. This is probably due to geotechnical soil characteristics or variation in topography and water table level, which indicates that this section is the most critical.

\section{CONCLUSION}

GIS is used in this study for slope stability analysis. ArcGis 9.3 is used to apply the Hovland formula both in 2D and 3D to calculate the safety factors. In overall, results indicate that the safety factors in 3D are always higher than those in 2D. Also this study demonstrates that
GIS can be used effectively for 3D and 2D slope stability analysis.

\section{REFERENCES}

Chang M, 2002. A 3D slope stability analysis method assuming parallel lines of intersection and differential straining of block contacts. Canadian Geotechnical Journal, 39: 799-811.

Hovland, H.J. 1977. Three-dimensional slope stability analysis method. ASCE Journal of the Geotechnical Engineering Division, 103(GT9): 971-986.

Chen, R.H., and Chameau, J.L. 1982. Three-dimensional limit equilibrium analysis of slopes. Geotechnique, 32(1): $31-40$.

Gens A, Hutchison JN, Gavounidis S,1988. Three dimensional analysis of slices in cohesive soils.Geotechnique, 38: 1-23.

Lam, L. and Fredlund, D.G. 1993. A general limit equilibrium model for three-dimensional slope stability analysis, Canadian Geotechnical Journal, 30(6): 905-919.

Huang C, Tsai C, Chen Y,2002. Generalized method for three-dimensional slope stability analysis. Journalof Geotechnical and Geoenvironmental Engineering; 128(10): 836-848.

Zheng, H. 2012. A three- dimensional rigorous method for stability analysis of landslides. Engineering Geology. 145: 30-40.

Carraea A, Cardinsli F, Guzzetti M, Reichenbach P,1995. GIS technology in mapping landslide hazard, geographical information systems in assessing natural hazards $[\mathrm{M}]$. Kluwer, Dordrecht, Netherlands, pp 135175 Anbalagan D. Landslide hazard evaluation and zonation mapping in mountainous terrain. Eng Geol 1992;32:269-77.

Van Westen CJ,1998. GIS in landslide hazard zonation: a view, with cases from the Andes of Colombia. In: Martin FP, Heywood DI, editors. Mountain environment and geographic information systems. Taylor \& Francis. p. $35-165$

Dai FC, Lee CF ,2001. Terrain-based mapping of landslide susceptibility using a geographical information system: a case study. Canadian Geotechnical Journal; 38: 911-923. 